Cultures \& Conflits

60 | hiver 2005

L'action humanitaire : normes et pratiques

\title{
La diversité culturelle et ses défis pour l'acteur humanitaire
}

Marion Harroff-Tavel

\section{(2) OpenEdition}

1 Journals

\section{Édition électronique}

URL : https://journals.openedition.org/conflits/1919

DOI : 10.4000/conflits.1919

ISSN : $1777-5345$

Éditeur :

CECLS - Centre d'études sur les conflits - Liberté et sécurité, L'Harmattan

Édition imprimée

Date de publication : 1 décembre 2005

Pagination : 63-102

ISBN : 2-296-00230-7

ISSN : 1157-996X

Référence électronique

Marion Harroff-Tavel, «La diversité culturelle et ses défis pour l'acteur humanitaire », Cultures \& Conflits [En ligne], 60 | hiver 2005, mis en ligne le 23 février 2006, consulté le 27 septembre 2021. URL : http:// journals.openedition.org/conflits/1919; DOI : https://doi.org/10.4000/conflits.1919

Ce document a été généré automatiquement le 27 septembre 2021.

Creative Commons License 


\title{
La diversité culturelle et ses défis pour l'acteur humanitaire
}

\author{
Marion Harroff-Tavel
}

1 Que faire pour prévenir les exactions de porteurs d'armes qui, au nom de la défense d'une identité, incitent à la haine en invoquant l'histoire, utilisent la religion pour justifier des actes de violence ou violent le droit humanitaire au nom du respect de leur culture? Comment éviter des attaques contre des biens culturels? Faut-il amputer un enfant victime d'une mine au Cambodge lorsque sa mère s'y oppose, de crainte qu'il n'ait qu'une jambe dans tous les cycles de renaissance qui suivront cette vie? L'acteur humanitaire doit-il tenir compte de discriminations sous prétexte qu'elles sont enracinées dans les cultures du pays où il opère ou doit-il ignorer ces discriminations au nom des principes qui sont les siens? C'est dans la vie quotidienne que l'acteur humanitaire est confronté à des interrogations et des choix qui posent parfois des problèmes éthiques. L'objet de cet article est de réfléchir à ces dilemmes concrets, qui s'inscrivent dans une problématique plus large, celle de la rencontre entre un droit humanitaire de portée universelle, une action humanitaire fondée, elle aussi, sur des principes universels, tel celui d'impartialité, et l'invocation de la culture par certains acteurs de conflits armés pour exprimer leur différence, voire rejeter l'autre.

2 Le texte est construit par étapes. La première étape consiste à préciser les notions de culture et d'identité telles que nous les comprenons, en tant qu'acteur humanitaire. Le cadre terminologique ainsi posé, nous nous interrogeons sur le conflit armé comme phénomène culturel. Puis sont évoqués les différents usages de l'identité et de la culture que font parfois les combattants, pour mobiliser leurs troupes ou justifier des violations du droit humanitaire. Dans ce contexte de conflit armé, nous nous concentrerons sur l'acteur humanitaire: en quoi une sensibilité culturelle est-elle importante pour l'acteur humanitaire et que doit-il savoir de lui-même pour travailler dans des contextes culturellement différents? Le décor de la guerre ainsi planté et les acteurs qui nous intéressent étant identifiés, c'est sur l'action humanitaire que nous nous interrogerons: comment développer une aptitude à lire des contextes culturellement divers? Comment intégrer les facteurs culturels dans des programmes 
humanitaires ? Enfin, quelle est l'utilité du droit humanitaire pour faire obstacle à la dérive identitaire de combattants, qui, bien souvent, manipulent la culture dans leur guerre psychologique?

3 Avant de nous lancer dans le périlleux défi d'aborder un sujet peu exploré sur le plan conceptuel par les acteurs humanitaires, mais auquel les événements de ces dernières années ont donné une importance accrue, un mot d'avertissement. C'est à partir d'un vécu que nous aborderons ce sujet, d'une longue expérience des conflits armés et de la connaissance des souffrances qu'ils provoquent. Ce n'est pas au travers du regard scientifique de l'anthropologue ${ }^{1}$.

4 Puissent ces quelques réflexions, évolutives, d'un acteur humanitaire contribuer à un débat dont nous mesurons l'importance, à l'heure où la mondialisation suscite tant d'incertitudes et de peurs. En effet, nos observations concrètes sur les théâtres de guerre, qui paraîtront parfois bien terre-à-terre au spécialiste, doivent être lues dans le contexte d'un monde où nombre de collectivités humaines se sentent menacées dans leur identité, leur langue, leurs traditions, leur religion et voient dans la mondialisation une culture occidentale « dominante».

Quel sens donner aux mots « culture » et « identité »?

5 Il peut paraître téméraire pour un acteur humanitaire de définir des notions sur lesquelles les spécialistes d'autres disciplines se livrent à des analyses bien plus profondes. Nous le ferons néanmoins, en sollicitant leur indulgence, pour que les prémisses conceptuelles de notre réflexion, dans cet article, soient claires, en particulier pour les acteurs humanitaires qui le liront.

Différentes compréhensions du terme "culture » coexistent ${ }^{2}$. Dans certaines écoles de pensée anthropologiques, la culture est perçue comme un tout homogène, territorialement délimité et historiquement enraciné. Le groupe culturel ainsi délimité partage un ensemble de normes, croyances, valeurs et comportements ainsi qu'une langue commune. Le réfugié ou le migrant passe du territoire d'une culture à celui d'une autre, traînant le fardeau de sa culture et cherchant à s'intégrer dans l'autre ou la rejetant d'emblée, quand il n'en est pas rejeté. Dans cette optique, un «choc de cultures » est possible. Une guerre de civilisations aussi. Une autre interprétation de la culture rejette l'idée de l'enracinement de celle-ci dans un territoire aux frontières délimitées. Elle est alors perçue comme un ensemble de valeurs et de pratiques en constante évolution. Des cultures se forment et d'autres s'éteignent, de telle sorte que la culture ne peut être assimilée à la tradition. L'histoire n'en est pas un élément constitutif, elle en est le support écrit. Ainsi conçue, la culture est construite autant qu'héritée du passé. Les mouvements de population contribuent à une hybridité culturelle des groupes sociaux et à la construction de réseaux de solidarités. Cette vision correspond mieux à un monde globalisé où l'Etat nation n'est plus tout puissant, où les flux, en particulier migratoires, se multiplient et les conflits armés se régionalisent. Elle met en doute le concept de guerre de civilisations, sans nier le fait que la montée des inégalités économiques, sociales et politiques entre des groupes différents sur le plan religieux, culturel ou linguistique est un facteur de tensions, tout comme l'absence de reconnaissance culturelle de l'autre et la discrimination qui en est le fruit ${ }^{4}$.

7 L'identité, telle que nous la concevons dans cet article, est une représentation collective, fruit de l'imaginaire du groupe. Cette représentation peut se cristalliser autour de plusieurs facteurs tels que la religion, l'ethnicité (comme outil de démarcation), le mode de vie (agriculture ou élevage), le lieu de résidence (vallée ou 
montagne), la langue ou encore le nationalisme (en particulier lorsque le groupe revendique un territoire). Selon François Thual, c'est la crainte du groupe d'être victimisé par l'autre (qui peut donner lieu à des surenchères), sa hantise d'être dépossédé de sa spécificité, qui forge son identités. D'où l'invocation d'un passé légendaire, le recours à des mythes, la résurgence du thème du peuple martyr qui se bat héroïquement pour sa survie. Notre expérience des conflits du Caucase (Abkhazie, Ossétie du Sud, Ossétie du Nord - Ingouchie, Nagorno-Karabakh, Tchétchénie) et des Balkans (Kosovo) nous a souvent conduits à entendre des doléances à propos de la destruction de biens culturels et des discours virulents de protagonistes de conflits sur les attaques portées contre leur langue ou sur la volonté de l'ennemi de les chasser d'un territoire dont ils estimaient être les premiers résidents.

Le conflit armé comme phénomène culturel

8 Les conflits armés actuels ne doivent pas être attribués de façon sommaire à des chocs de culture, mais le conflit armé, en tant que tel, est un phénomène culturel.

9 Première proposition : il n'y a pas un rapport univoque de causalité entre cultures et conflits, même si la conscience identitaire liée à une culture, lorsqu'elle s'affirme en opposition à l'autre, peut être source de violence et si certaines cultures incluent des traditions plus belliqueuses que d'autres. Trois raisons nous amènent à ce point de vue. D'abord, la culture ne contribue pas uniquement à marquer des différences entre les peuples, elle permet aussi aux peuples de communiquer par delà leurs différences. En Croatie, la Croix-Rouge de la jeunesse en a fait la démonstration en organisant, avec le concours des enseignants, à la fin des années 1990, des expositions itinérantes d'art et de poésie sur l'action Croix-Rouge et le principe d'humanité, pour contribuer à diminuer la peur et la méfiance entre Serbes et Croates. Ensuite, aucune entité culturelle n'est homogène (des courants politiques, classes sociales, intérêts économiques s'y affrontent), donc il peut y avoir des solidarités entre des individus ou groupes appartenant à des cultures différentes. Enfin, il serait naïf de réduire la guerre à des différences de cultures, alors qu'elle est souvent froidement planifiée pour servir des intérêts matériels ou une volonté de puissance. La référence culturelle, ethnique, religieuse ne doit pas occulter le fait que la volonté d'appropriation des ressources économiques - pétrole, diamants, bois précieux, minerais, terre, eau - est un élément moteur de nombre de conflits actuels ou passés. Le Libéria, la Sierra Leone et le Soudan sont des pays où une telle hypothèse a été envisagée 6 .

10 En quoi la guerre est-elle un phénomène culturel ? La façon dont la guerre se déroule est influencée par la culture. Le CICR a fait à ce propos une expérience intéressante en favorisant l'analyse, par un groupe d'historiens somaliens (histoire orale), des règles que les guerriers somaliens observent traditionnellement lors les combats. Cette étude met en évidence le principe d'immunité de certains groupes (femmes, enfants, hommes de religion, invités honorés et chefs des communautés); elle montre la façon dont les faibles sont sous la protection spéciale de Dieu et explique comment les prisonniers de guerre et les blessés et malades doivent être traités. L'importance de l'honneur, individuel et collectif, et de la réputation, y est soulignée ${ }^{7}$. Certes, la modernisation de la technologie de la guerre et des armes, parmi d'autres facteurs, a peut-être rangé ces traditions dans les livres d'histoire, mais elle illustre l'idée que les groupes sociaux ont des motifs de faire la guerre, des façons de la mener et des moyens de la régler qui leur sont propres. 
11 La guerre donne également lieu à des recompositions identitaires. D'une part, elle oblige souvent les individus à déclarer une appartenance, et le choix de cette appartenance peut être dicté par de multiples facteurs, dont l'un des plus importants est la sécurité. Lorsque l'Etat est en pleine déliquescence et ne peut protéger ses citoyens, la famille se tournera souvent vers le chef de guerre ou le groupe de solidarité restreint qui lui procurera la plus grande protection. Ce choix est souvent dramatique. Ainsi, à Sarajevo, lors de l'embrasement de l'ex Yougoslavie, nombre de citoyens ne souhaitaient pas s'identifier à un groupe ethnique - serbe, croate ou musulman. Ils n'ont pas pu se soustraire à ce choix. D'autre part, la recomposition identitaire est souvent le fait des déplacements de population. Les groupes se structurent sur une base de réseaux d'entraide, qui transcendent les frontières, dans lesquels les diasporas jouent un rôle important. Le cas du Nagorno Karabakh est un exemple intéressant, du fait de l'engagement politique et financier de la diaspora arménienne installée principalement sur la Côte ouest des Etats-Unis et en France.

Les usages de l'identité et de la culture dans les conflits armés

Il y a différentes façons d'instrumentaliser la culture et l'identité dans les conflits armés. Nous en évoquerons deux dont nous avons été le témoin : d'une part, le recours à ces notions pour mobiliser des combattants; d'autre part, leur invocation pour justifier des violations du droit humanitaire.

13 Des revendications identitaires, qui peuvent apparaître légitimes, donnent parfois lieu à un embrasement rapide de l'ensemble d'une communauté exaltée par des discours qui se nourrissent de la peur de l'autre en même temps qu'ils l'alimentent. Chacun finit par être englouti dans une vision manichéenne que développent aussi bien les hommes et les femmes politiques, que les journalistes, le clergé et les intellectuels. Dans des pays en guerre, les stratèges de l'identitaire sont souvent intoxiqués par leur propre discours. Ils lisent tous les événements à la lumière de référents identitaires. Ils finissent par plus s'émouvoir de l'incendie de biens culturels, d'un lieu de culte ou d'une bibliothèque, que des exécutions sommaires de civils engendrées par leur politique. Et l'on en vient à s'apercevoir que dans leur imaginaire, une guerre de civilisation a bien lieu, alors que l'affrontement est principalement le fruit d'une situation économique désastreuse et de ses effets sociaux.

14 A cet égard, le discours sur la guerre des civilisations (une notion trop globale pour être réellement utile) est inquiétant car il contribue à la construction de l'imaginaire collectif et finira, nous le craignons, par produire ce qu'il prétend étudier. L'analyse, tant commentée, des guerres de civilisations en viendra à participer à la création de l'objet d'analyse, en alimentant la crainte des civilisations auxquelles nous n'appartenons pas. Et la réduction, bien souvent, de la civilisation à une ère où prédomine une religion (chrétienne, islamique, confucéenne, orthodoxe, etc.) rend cette crainte encore plus forte, car la religion est souvent invoquée pour provoquer ou justifier la violence. Cette violence est généralement fondée, comme nous l'avons vu, sur la perception d'une menace à sa propre religion ou d'une agression contre elle. Le discours religieux est alors exploité à des fins partisanes, pour mobiliser des combattants, parfois avec sincérité, parfois avec un froid calcul.

15 Le deuxième usage de la culture que nous aimerions évoquer est son utilisation, par les détenteurs du pouvoir, pour justifier leur incapacité à appliquer un droit humanitaire dont ils nient rarement la pertinence. Et parfois, il n'est pas si simple de leur répondre, 
d'où l'importance de ne pas se laisser impressionner par leurs propos, tout en gardant un esprit ouvert face à leurs arguments. Il y a des limites à poser au relativisme.

A ce propos, deux exemples du Sud Caucase nous viennent à l'esprit. Le premier est la détention d'otages en mains privées. Certes, Alexandre Dumas a écrit des pages captivantes sur l'origine ancienne de la prise d'otages dans cette région ${ }^{8}$ et nombre de boîtes noires laquées, traditionnelles, représentent des jeunes filles caucasiennes enlevées dans un paysage de neige sur un traîneau tiré par des chevaux fougueux (sans que les visages féminins ne trahissent la violence qui leur est faite). Ceci n'a toutefois rien à voir avec la détention d'une vieille femme, dont le prix est fixé (bien moins cher qu'un homme jeune) et qui attend, dans l'angoisse, d'être échangée contre un membre de la famille qui la détient, prisonnier des siens de l'autre côté de la ligne de front. Certains interlocuteurs nous ont dit que la tradition caucasienne de la détention en mains privées, en violation de l'interdiction de la prise d'otages, et l'échange de détenus par des familles constituaient, dans les conflits armés, une pratique plus humaine que la prison. Il y a des logiques culturelles dans lesquelles l'acteur humanitaire ne peut pas entrer, même s'il est légitime qu'il s'interroge sur les conditions de vie les meilleures pour le captif (en famille ou dans une prison d'Etat ?).

Un autre exemple est la mise en place de corridors dits «humanitaires». Avant d'assiéger une ville ou un village encerclé, la tradition, nous a-t-il été dit en réponse à nos protestations, est de laisser les vieillards, les femmes et les enfants sortir par un corridor humanitaire, en confisquant les biens de valeur au passage. Ceci protègerait leur vie. Après leur départ qui devait s'opérer en un temps record, licence était donnée pour des combats sans merci contre les hommes qui voulaient se battre ou n'avaient pu fuir et pour le pillage des biens abandonnés. Le droit humanitaire ne permet pas de telles pratiques.

18 Somme toute, dans les conflits armés, l'appartenance culturelle peut conduire à la mort, à la torture, à l'exil forcé, à la marginalisation. L'acteur humanitaire soulage, par son action de secours, certaines des souffrances provoquées par ces comportements. Il exige le respect du droit humanitaire, qui interdit les exécutions sommaires, la torture et les déplacements forcés de population et qui protège les biens culturels. Cela fait partie de ses activités traditionnelles. Reste à déterminer l'utilité d'une sensibilité culturelle pour mener cette action humanitaire.

En quoi une sensibilité culturelle est-elle importante pour l'acteur humanitaire?

Certains affirment que l'acteur humanitaire court le risque, en s'intéressant à la culture, de passer à côté de la vraie nature des conflits armés dans lesquels il vit, dont les origines sont avant tout économiques et politiques. Une analyse des conflits privilégiant la culture reviendrait à occulter l'exploitation, les inégalités sociales, les injustices dans la répartition des ressources et du pouvoir. Ceci nous paraît être un faux problème. Il ne s'agit pas de privilégier un mode d'analyse par rapport à un autre, mais plutôt d'adopter différentes perspectives pour mieux comprendre.

20 Ces craintes sont exagérées. En premier lieu, s'intéresser à la culture des personnes affectées par la violence armée est une manifestation de respect et d'intérêt envers des personnes qui ont subi souvent une grande perte de confiance en elles-mêmes. Admirer des enluminures arméniennes à Erevan ou observer, avec un intérêt sincère, de vieilles cartes d'Asie centrale à Douchanbe ouvre les portes de la compréhension mutuelle. La culture est bien souvent, mais pas toujours, une source de fierté pour ceux qui s'en réclament. C'est un espace de rencontre intellectuel, esthétique, voire émotionnel, qui 
peut être le prolongement d'un rapport de confiance et le prélude d'une relation constructive lorsqu'il s'agira de débattre de questions humanitaires.

En deuxième lieu, intégrer la compréhension de la culture de l'autre dans ses projets, que ce soit au niveau idéologique, social ou pratique, permet de mieux répondre aux besoins, d'éviter de transgresser sans le savoir des interdits (ce qui peut poser des risques pour la sécurité) et d'être plus efficace. Il faut, par exemple, comprendre comment les facteurs culturels ont un impact sur la façon dont les gens vivent la guerre. Des déplacés africains peuvent se sentir hantés par les souffrances des ancêtres qu'ils n'ont pas enterrés comme il se doit. La relation à la mort diffère selon les sociétés (retour au néant pour les uns, renaissance pour d'autres). Il en va de même pour la gestion du deuil et le soin accordé aux sépultures9. Il est aussi utile de s'enquérir des codes de conduite. Les Thaïs, par exemple, fournissent aux étrangers un guide pratique en la matière pour qu'ils ne commettent pas d'impair.

En dernier lieu, le droit humanitaire - c'est-à-dire les règles qui doivent être respectées dans les conflits armés aussi bien envers des catégories de personnes protégées que dans la conduite des hostilités - exige le respect des biens culturels et, au-delà de ces biens, de communautés qui ont droit à une identité. Le délégué du CICR, qui doit veiller au respect du droit humanitaire, est tenu de le faire connaître et d'entreprendre des démarches lorsque des biens culturels sont en péril. La destruction programmée des statues de Bamiyan en Afghanistan, chères à la population hazara, a tristement remis cette responsabilité à l'ordre du jour.

Un impératif de modestie s'impose toutefois. Les acteurs humanitaires ne peuvent pas aller très loin dans leurs analyses. En effet, rares sont les anthropologues parmi eux, et le recours aux consultants est limité par des contraintes financières. Les collaborateurs nationaux avec lesquels les délégués du CICR travaillent sont d'un très grand secours dans cette entreprise, de même que les membres des Sociétés de la Croix-Rouge et du Croissant-Rouge qui aident beaucoup le CICR à comprendre le milieu dans lequel il évolue ; ils sont toutefois, pour la plupart, issus d'un même moule socio-économique, le milieu urbain aisé (tout au moins aisé avant que n'éclate le conflit), ou alors ils ont parfois une appartenance ethnique qui influence leurs analyses. La barrière linguistique entre les délégués et les communautés locales ne facilite pas la compréhension mutuelle - pas plus d'ailleurs que l'agressivité de certaines « victimes » envers les acteurs humanitaires, qu'ils rendent responsables de leurs malheurs à défaut de pouvoir s'en prendre au monde politique. Enfin, l'urgence ne permet pas des études sérieuses des cultures sous-jacentes aux environnements conflictuels, même si la présence du CICR sur des théâtres d'opérations durant de longues années (Soudan, Irak, Colombie, Afghanistan, Sri Lanka, etc.) permet une meilleure connaissance.

Que doit savoir l'acteur humanitaire de lui-même pour s'insérer dans un contexte culturellement différent?

L'acteur humanitaire ne doit pas s'exclure de l'analyse. Il n'est pas dans un acte unilatéral d'observation et de projection de sa spécificité sur l'autre. Pour entrer en dialogue, il doit se connaître, accepter ses limites et réaliser qu'il est lui-même objet d'étude. Il est dans la même situation que l'homme d'affaires d'une firme étrangère, le journaliste ou l'observateur des Nations Unies plongé au cœur de la guerre.

L'acteur humanitaire est porteur de plusieurs identités qui seront autant d'énigmes pour ses nouveaux interlocuteurs, amis, voisins. Ainsi, il est à la fois un acteur de l'humanitaire, le représentant d'une organisation qui a un mandat et des principes 
d'action, un membre d'une catégorie professionnelle parfois dotée d'une éthique ou d'une culture spécifique et un être humain avec un parcours de vie.

D'abord, c'est un acteur de l'humanitaire, dont l'éthique, tout au moins pour le Mouvement international de la Croix-Rouge et du Croissant-Rouge, peut être décrite par une mosaïque de mots: urgence, secours à l'individu, impartialité, solidarité, approche normative face aux exactions. Il n'existe pas un modèle unique de l'humanitaire, certaines sociétés, en Asie ou en Afrique, privilégiant, par exemple, l'intérêt collectif à celui de l'individu. Toutefois l'humanitaire, quels qu'en soient les contours, est un facteur identitaire, comme l'est le développement pour ceux et celles qui en sont les agents.

Ensuite, le même acteur humanitaire appartient à une institution. Le délégué du CICR, par exemple, se qualifie parfois de nomade. Il aspire à se sentir chez lui partout et pour qu'il en soit ainsi, est porteur d'une culture institutionnelle reconnaissable globalement, tout en étant adaptée localement ${ }^{10}$.

En troisième lieu, ce délégué aura l'éthique ou la culture de sa profession. C'est elle qui dictera le geste du médecin confronté à la souffrance, qui conduira l'anthropologue à s'interroger sur les effets à long terme de son geste ou le technicien à chercher des résultats rapides, efficaces, à moindre coût pour l'institution.

En dernier lieu, l'acteur humanitaire, c'est vous et moi. Chacun de nous a une identité nationale, des convictions, un parcours de vie. A titre d'exemple, le délégué genevois, homme, protestant et la déléguée africaine, femme, musulmane ont en commun l'appartenance à la culture institutionnelle du CICR, mais, en dehors de cela, une perception du bonheur, de la justice, du religieux, du rapport entre êtres humains, peut-être fort distincte.

L'intérêt de comprendre les différentes composantes de l'identité vécue du délégué se justifie par le fait que, pour communiquer avec l'autre, il faut bien se connaître soimême. Souvent, l'acteur humanitaire a le sentiment de culpabilité de celui qui se sent intrus dans le monde de l'autre, qui voudrait faire oublier l'arrogance qu'on lui attribue. Il est conscient, lorsqu'il vient d'un pays en paix, de la situation infiniment privilégiée qui est la sienne au regard de la condition des victimes de conflits qu'il rencontre. Certains tombent dans le piège de la fascination pour l'exotisme. Ils s'assimilent à ceux dont ils recherchent l'acceptation, oubliant qu'être authentique force le respect. Somme toute, la meilleure voie serait que l'acteur humanitaire, plutôt que de comparer sa vision à celle des autres dans une approche ethnocentrique, essaye de se mettre à la place de l'autre, pour comprendre le regard que ce dernier porte sur lui. Il serait souvent surpris par la nature critique de ce regard.

Comment développer une aptitude à lire des contextes culturels différents ?

31 A quoi doit s'intéresser l'acteur humanitaire s'il désire progresser dans la compréhension des valeurs, croyances, comportements, pratiques des gens au milieu desquels il vit?

Sans prétendre à l'exhaustivité, il s'agit, en premier lieu, de connaître l'histoire de ce peuple, en particulier ses moments tragiques, les motifs des conflits et la façon dont ils se règlent. Ainsi, une étude commandée par le CICR sur le règlement des conflits tribaux au Yémen évoque l'éruption fulgurante de la violence tribale à propos d'un fait divers (homme d'une tribu tué dans un accident de voiture par un homme d'une autre tribu) et la rapidité du règlement du différend par la justice coutumière, selon des 
normes ancestrales ${ }^{11}$. Mieux vaut en être conscient plutôt que de s'immiscer maladroitement dans ce type de situation.

En second lieu, l'acteur humanitaire doit s'intéresser à la façon dont son geste est perçu. Comment, par exemple, communiquer avec des intellectuels et décideurs africains si on ignore que pour certains d'entre eux, l'humanitaire n'est pas un impératif de solidarité, dicté par la compassion, mais un impératif de justice globale, une forme de réparation pour les souffrances causées par l'esclavage et le colonialisme, un dû et certainement pas un don?

En troisième lieu, l'acteur humanitaire doit identifier la «vulnérabilité culturelle » de certains groupes de population; il s'intéressera aux comportements qui peuvent engendrer la vulnérabilité (telles des pratiques obscurantistes) et à la façon dont la communauté gère les différences (par exemple, le rejet des individus handicapés ou des femmes dont on dit qu'elles ont déshonoré la communauté) ${ }^{12}$. En effet, un certain nombre de problèmes pratiques que peuvent rencontrer des délégués, médecins, nutritionnistes ou ingénieurs, proviennent de croyances, par exemple la conviction de communautés Dinka au Soudan qu'un nourrisson souffre de diarrhée lorsque sa mère a travaillé trop longtemps au soleil et que son lait a atteint une température exagérée ${ }^{13}$.

Il est enfin utile de comprendre le droit non écrit, les traditions, mythes et légendes, les symboles, les comportements requis ou prohibés, les pratiques (nutrition, habitat, santé). Pour appréhender, par exemple, la façon dont les porteurs d'armes analysent leurs comportements en termes de droit international humanitaire, mieux vaut avoir une notion des codes de comportement locaux (respect des personnes âgées ou interdiction de tuer dans le dos, par exemple).

Ce qui est encore plus aléatoire, c'est de comprendre l'impact du conflit sur les relations de pouvoir dans une société, des relations de pouvoir en partie - bien sûr, pas exclusivement - dictées par la culture. Prenons le cas des anciens, des sages. La guerre accélère souvent la relève des générations et modifie la distribution des rôles, lorsqu'elle ne fait pas perdre aux anciens leur crédibilité dans la communauté. Nous ne pouvons oublier les arrangements locaux conclus par des anciens avec les forces armées ennemies dans une région conflictuelle. Ces forces avaient demandé aux anciens de faire pression sur les jeunes combattants pour qu'ils déposent les armes et quittent le village avant une certaine date. En échange, l'assurance était donnée que le village ne serait pas bombardé. Les jeunes miliciens remettaient aux anciens quelques vieux fusils et quittaient de nuit les agglomérations pour protéger leurs familles. Mais vingt-quatre heures avant la date butoir fixée par l'ultimatum, alors que les anciens s'apprêtaient à remettre les armes aux soldats ennemis, les bombardements commençaient. Et le même scénario recommençait dans un autre village, avec une étonnante systématique. Quelle crédibilité restait-il aux anciens qui avaient eu la crédulité de faire confiance à l'ennemi et privé le village de ses protecteurs ? Même si la figure du sage n'est pas remise en cause, les jeunes d'aujourd'hui, lorsqu'ils seront vieux et investis de l'autorité des anciens, la réinventeront en fonction de leur parcours de vie. Leur pouvoir ne proviendra peut-être plus du statut de leur famille, influencé par le patrimoine foncier de celle-ci, mais de leur aptitude à s'insérer dans les flux commerciaux et financiers dictés par la mondialisation, qui seront la nouvelle source de richesse - ou la nouvelle cause de pauvreté.

L'acteur humanitaire aura toujours tout à apprendre, du moins ce que le milieu dans lequel il vit voudra bien lui permettre d'approcher. Souvent, il n'aura tout simplement 
pas accès au monde réinventé par les personnes qu'il cherche à assister. C'est particulièrement patent dans le monde carcéral, où, dans certaines prisons d'Amérique latine, les prisonniers s'enfermaient dans la prison pour y vivre dans ce que nous désignerons témérairement par le terme de " microculture ». La prison avait en réalité deux enceintes, celle qui isolait le monde carcéral de l'extérieur et privait le captif de sa liberté et celle qu'il érigeait lui-même pour protéger ce qui lui restait de liberté et déterminer son mode de vie. Ces deux enceintes étaient séparées par un sas que le délégué du CICR était l'un des seuls à franchir sans pouvoir pour autant prétendre être à même de comprendre l'univers clos où il accomplissait le geste humanitaire. Alors, si le fait de parler de nous et de l'autre nous gêne, car c'est ériger une barrière symbolique, reconnaissons que parfois cette muraille existe souvent malgré nous.

Comment intégrer les facteurs culturels dans les projets humanitaires?

Comment peut-on intégrer les différences culturelles dans nos attitudes et dans la conception de projets humanitaires? En prenant quels risques et jusqu'où? Tels sont les trois sujets que nous souhaiterions maintenant aborder.

Les exemples foisonnent de dilemmes auxquels les délégués ont été confrontés et des voies qu'ils ont dû emprunter par respect de la culture ou tout simplement du mode de vie d'autrui. L'eau offre de multiples illustrations. Au Sud Soudan et dans la Corne de l'Afrique, par exemple, dans certaines populations, lorsqu'il y a de l'eau, le bétail boit en premier. Le bétail est parfois vacciné avant les enfants, car le bétail est le garant de la survie de la communauté. S'il meurt, les hommes mourront aussi. En Irak et au Darfour, en raison de pratiques religieuses (il faut se laver diverses parties du corps avant la prière), certaines communautés font une consommation d'eau plus grande et les critères de distribution doivent être plus généreux. En Jordanie, à la veille de la guerre du Golfe, lors de l'évacuation des travailleurs immigrés du Koweït, en aoûtseptembre 1990, il a fallu construire des sites d'hébergement dans un camp en fonction de l'origine et de la culture des personnes accueillies. En raison du manque d'espace, certaines structures devaient être partagées. Or, le rapport à l'eau de communautés distinctes, provenant du Soudan, du Bengladesh, d'Inde, d'Egypte ou encore de Thaïlande, n'est pas le même. Ne pas en tenir compte peut être la source de grandes tensions entre ces groupes. Bien entendu, ce qui est dit pour l'eau est aussi valable pour la nourriture ou l'habitat.

L'approche participative est le meilleur moyen d'écoute et de consultation des populations. Elle permet de mieux comprendre ce qui cause une souffrance. Ainsi, dans certaines sociétés le prisonnier a besoin d'un espace privé et souffre de la promiscuité résultant du partage d'une cellule, alors que dans d'autres il partage plus facilement une vie sociale avec d'autres et se sent à l'aise dans le groupe. Par ailleurs, si la cause de la souffrance diffère, il en va de même de la façon dont l'individu la traduit, ce qui n'est perceptible que dans le dialogue. On est parfois surpris de la sobriété avec laquelle certains prisonniers racontent les horreurs qu'ils ont vécues. L'approche participative permet alors d'identifier les réponses appropriées. Enfin, cette approche est le moyen d'agir ensemble, de sortir de la logique du don de l'un et de la dépendance de l'autre, d'échapper à la relation de pouvoir entre l'acteur humanitaire et la «victime» qui, bien souvent, souffre qu'on ne lui reconnaisse que cette « qualité », surtout si elle a des ressources propres. L'approche participative n'est donc pas un luxe, même si ce mode d'action n'est pas toujours possible car, dans l'urgence, il faut aussi savoir décider pour l'autre. 
41 Par ailleurs, il faut être conscient des dangers de l'intégration des différences culturelles dans les programmes humanitaires. Le premier est de se perdre dans des différences pseudo-culturelles. Les besoins de certains groupes de population sont les mêmes partout, qu'ils soient agriculteurs, éleveurs ou menuisiers. Le paysan suisse et le paysan africain auront des problèmes similaires d'accès à l'eau, aux pâturages, aux marchés. Et les bergers musulmans, catholiques ou bouddhistes ont un langage commun. Il est donc souvent plus important de comprendre les mécanismes commerciaux que les différences culturelles ou religieuses. Le second danger est d'expliquer les échecs de certains projets par des différences culturelles. C'est trop facile. Bien souvent, les résistances opposées au projet humanitaire émanent de tout autres considérations.

Somme toute, il y a des limites au respect des particularismes culturels. Si la culture exclut de certains villages les gens qui ont enfreint des tabous et qui ne méritent plus l'assistance humanitaire, les laisser mourir de faim serait contraire à l'éthique du CICR. C'est le droit international humanitaire et les Principes fondamentaux de la CroixRouge et du Croissant-Rouge qui aideront à déterminer le moment où, comme le disait un médecin, après avoir ôté toutes les pelures successives de l'oignon on en arrive au coeur où le compromis n'est plus possible sous peine de se trahir soi-même.

Le droit humanitaire comme rempart aux dérives de conflits identitaires

43 Le droit humanitaire, comme évoqué précédemment, est un ensemble de règles qui protègent ceux qui ne prennent pas part aux hostilités (par exemple, les malades et les civils) et ceux qui ne prennent plus part aux hostilités (tels les blessés ou les prisonniers). Il contient aussi des règles relatives à la conduite de la guerre. Ce droit présente un intérêt particulier comme rempart aux dérives de conflits identitaires de par sa nature, mais aussi en raison de dispositions spécifiques qu'il comporte sur la protection des biens culturels. Le faire connaitre et respecter dans des contextes culturellement différents est un défi.

Le droit humanitaire dans des conflits identitaires est la confrontation entre une approche inclusive et une démarche d'exclusion. En effet, l'un des principes de base de ce droit universel - auquel sont parties cent quatre-vingt-douze Etats - est la nondiscrimination. Les individus doivent être traités sans distinction de caractère défavorable basée sur le sexe, la race, la nationalité, la religion, les opinions politiques ou tout autre critère analogue. Ce principe n'exclut toutefois pas des distinctions légitimes, qui ne seraient pas "de caractère défavorable " pour tenir compte de la situation particulière de certaines catégories de personnes comme les enfants, les femmes enceintes ou les mères d'enfants en bas âge. Le droit humanitaire ne fait pas non plus de discrimination entre les belligérants, qui sont égaux devant le droit de la guerre. Ils doivent le respecter de manière égale quelle que soit la légitimité ou la licéité de la cause qu'ils défendent. Le fait de considérer que l'on mène une guerre juste ou le fait d'avoir été agressé n'autorise pas le recours à des méthodes ou moyens de combat prohibés. Enfin, l'engagement souscrit par les Etats de respecter le droit humanitaire est unilatéral et non réciproque; il ne dépend pas du respect de ce droit par l'adversaire. Il y a donc dans le droit humanitaire, comme dans l'action humanitaire, trois éléments essentiels : d'abord, un respect égal pour tous les hommes et toutes les femmes, tous les Etats, toutes les cultures; ensuite, le rejet de toute discrimination à leur endroit, enfin, la conviction fondamentale que chaque être humain a droit au respect de sa dignité, donc de son honneur, de ses convictions, de ses 
liens familiaux. C'est un message qui a une valeur symbolique dans un monde où les identités deviennent meurtrières.

Le droit humanitaire comporte également des dispositions relatives à la protection des biens culturels. Face à la destruction délibérée de monuments, de lieux de culte et d'œuvres d'art dans les conflits armés, il est urgent de faire connaître ces dispositions. En effet, ces biens n'ont pas qu'une valeur esthétique et matérielle, ils sont la mémoire des peuples du passé, de leur identité, de leur grandeur ${ }^{14}$. La pierre angulaire de la protection dont ils font l'objet est la Convention de La Haye de 1954, son Règlement d'exécution, ainsi que ses Protocoles de 1954 et 1999. D'autres instruments contiennent des dispositions relatives à ce sujet, en particulier les Protocoles de 1977 additionnels aux Conventions de Genève de 1949 et le Statut de la Cour pénale internationale adopté à Rome en juillet 1998. Les parties au conflit ont l'obligation, en vertu de ces instruments, de prendre toutes les mesures nécessaires pour épargner ces biens, à condition qu'ils ne soient pas employés en même temps à un but militaire. Ces biens doivent être marqués par un signe distinctif visible et notifié d'avance. Le Statut de la Cour pénale internationale rend celle-ci compétente pour juger les personnes soupçonnées d'avoir enfreint l'interdiction des attaques contre les biens culturels dans le cadre d'un conflit armé international ou non international ${ }^{15}$.

La règle est ainsi posée. Mais comme la culture divise les êtres humains autant qu'elle les unit, l'acteur humanitaire ne peut qu'être consterné au souvenir des attaques contre Dubrovnik ou à la vision, dans les Balkans de mosquées, d'églises et de monastères détruits par les belligérants. Les menaces qui pèsent sur les biens culturels ne cessent de croître à une époque où la composante psychologique et symbolique de la guerre prend de l'ampleur, comme en témoigne l'attaque contre les Twin Towers de New York. Une action décisive doit donc être menée pour protéger les trésors de l'humanité ou, plus modestement, les trésors de communautés fières de leurs monuments, leurs sites archéologiques, leurs livres et manuscrits, leurs musées ou leurs dépôts d'archives. L'action du CICR inclut la diffusion des règles du droit humanitaire, l'invitation adressée aux Etats à prendre, sur le plan national, les mesures leur permettant de respecter ces règles au cas où un conflit viendrait à éclater et des démarches auprès d'eux, le cas échéant ${ }^{16}$.

Le droit humanitaire a une portée universelle au vu du nombre d'Etats parties aux traités qui lui donnent force de loi. Il faut toutefois reconnaitre que ce droit est parfois perçu comme un corps étranger dans certaines sociétés, comme d'autres branches du droit international. D'où l'idée que le CICR a eue - et dont il connait maintenant les défis - d'examiner les convergences entre ce droit universel et des législations ou coutumes locales ${ }^{17}$. Le CICR a notamment facilité la publication d'un ouvrage sur le droit humanitaire et les traditions Maya ${ }^{18}$ et il s'apprête à publier une étude menée dans les îles du Pacifique, destinée à mieux comprendre comment les sociétés traditionnelles réglementent leurs différends et les résolvent. Un professeur d'université de Suva, aidé par des étudiants, en est le maître d'oeuvre.

A l'origine, l'enthousiasme pour ce type de recherche a été grand. Il le reste, mais avec une compréhension légèrement différente de leur raison d'être. Le but n'est pas une comparaison de règles, même si celle-ci présente par elle-même un grand intérêt, mais une meilleure insertion dans des environnements qui sont étrangers à l'acteur humanitaire. C'est une façon d'entrer en dialogue, d'expliquer qui l'on est, d'être à l'écoute. L'objectif a changé car plusieurs risques sont devenus évidents avec le passage 
du temps. Quatre d'entre eux préoccupent particulièrement l'institution : le risque de manipulation par le CICR de la culture locale si on choisit ce qui correspond au droit humanitaire en écartant toute pratique traditionnelle qui lui serait contraire; le danger concomitant de s'associer à un groupe donné de la population dans l'analyse de la culture locale et de conférer à ce groupe un pouvoir exagéré qui porterait atteinte à la perception de neutralité du CICR; la difficulté d'identifier le fond commun qui permet de tracer des convergences avec le droit humanitaire dans des sociétés multiculturelles; la crainte d'ethnocentrisme dans une approche consistant à démontrer que tout ce qui est dans la culture locale relève de l'universel.

Il est toutefois une approche dont l'intérêt est constant, c'est le choix de vecteurs de communication du droit humanitaire qui parlent au coeur et à la raison des interlocuteurs que le CICR souhaite persuader de le respecter ${ }^{19}$. Pour entrer dans une relation constructive, il faut avoir cette capacité de traduire un message qui se veut universel ou un questionnement qui sert de base à une discussion sous une forme localement appropriée : le théâtre en Somalie et au Nigeria, le football en Colombie ${ }^{20}$, le cirque d'enfants des rues en Ethiopie, les proverbes du Kivu ou la danse en Angola. Il ne s'agit alors pas tant d'une approche interculturelle que, plus modestement, d'une adaptation contextuelle du mode de communication du CICR.

Culture et empathie

Que conclure de cette analyse fondée sur les expériences faites par le CICR pour mieux intégrer les aspects culturels dans ses projets en faveur des personnes affectées par les conflits armés et pour obtenir un meilleur respect du droit humanitaire par les porteurs d'armes et les hommes politiques?

51 "La culture n'est pas un luxe », comme l'écrit le gouvernement suisse ${ }^{21}$. C'est une force psychique qui semble permettre à l'être humain d'être plus résistant face à la maladie et aux traumatismes. Sorti de son milieu culturel (qui n'est pas, nous l'avons vu, ancré dans un territoire), il perd ses repères et sa capacité psychique à résister aux chocs de la guerre est affaiblie. Dans quelle mesure l'appartenance culturelle renforce-t-elle la résilience ? Cette question, l'acteur humanitaire se la pose parfois.

Les biens culturels, qui sont la mémoire collective d'un peuple, doivent être respectés. Il est faux de dire «A quoi bon se mobiliser pour des statues ou des musées quand tant de vies humaines sont en péril?" L'un n'exclut, bien entendu, pas l'autre. Mais méconnaître un patrimoine qui constitue l'identité d'un peuple, c'est nier la valeur de cette identité. C'est une insulte et une cause de souffrances lourdes de dangers pour l'avenir.

La culture de l'autre sous-tend toute relation humaine et s'interroger à son sujet est la responsabilité de chacun de nous, avec les instruments dont nous disposons de par notre parcours de vie. Chacun a son passé, son bagage, son image et c'est la rencontre qui compte. Une rencontre qui implique de comprendre sa propre identité évolutive et la façon dont elle est perçue avant même d'analyser un environnement socio-culturel en perpétuelle mutation. Alors, si les instruments de l'anthropologie, de la psychologie, de la philosophie peuvent faciliter cette rencontre, pourquoi se priver d'y recourir?

Somme toute, l'acteur humanitaire est un être humain, bien intentionné, qui en rencontre un autre, pas toujours convaincu d'emblée de ses bonnes intentions, parce que, dans la guerre, il ne reste plus grand chose de solide, si ce n'est dans un cercle très restreint. Créer le lien avec un autre être humain qui souffre, qui est humilié, qui se sent dans un état de dépendance, est une affaire de tact, d'écoute, de respect, en un 
mot, d'empathie. Le secret de la réussite est double. D'une part, il faut avoir un esprit ouvert et une sensibilité aux différences, qui requiert tolérance, mais aussi parfois sens des limites et des priorités. D'autre part, il importe de ne pas présumer que les principes et valeurs de l'action humanitaire, telle que nous la concevons, sont spontanément compris et acceptés par ceux qui en bénéficient et par les groupes et individus qui se font la guerre. Les uns verront peut-être, dans l'action humanitaire, un impératif de justice davantage qu'une exigence de solidarité ou relativiseront l'importance de l'impartialité. Les autres construiront des justifications morales à leurs exactions. Apprendre à écouter, connaître, situer l'autre dans son contexte culturel est le cheminement d'un véritable dialogue, qui ouvre la voie à l'action humanitaire.

Plutôt que d'assimiler les cultures à des plaques continentales et de renforcer ainsi une logique de confrontation, le défi actuel est d'apprendre à nouer le dialogue, individuellement ou collectivement, dans un monde où les différences s'accélèrent et la tendance à diaboliser l'autre va croissant. Ne faisons pas apparaître le «dialogue interculturel » comme une solution à la recrudescence du terrorisme, sans même savoir quelles cultures nous avons à l'esprit ou en assimilant l'Islam et l'Occident à des cultures ou à des civilisations, alors que ce qu'il faut promouvoir, c'est le dialogue entre des êtres de bonne volonté, de tous les horizons. Il nous faut apprendre à maîtriser notre peur de l'étranger dans ce qu'il a de différent. Faisons en sorte que les générations futures aient la possibilité de s'instruire, pour découvrir la richesse de la culture à laquelle elles s'identifient, pour contribuer à son évolution et pour s'ouvrir à d'autres cultures, dont elles adopteront peut-être certains traits et qu'elles apprendront à respecter. Elles sauront ainsi mieux résister aux sirènes qui les appellent à "défendre » leur identité de façon violente et elles découvriront un patrimoine commun de l'humanité, qui leur permettra d'accéder à un universel dont elles seront fières.

\section{NOTES}

1.. L'auteur de cet article est conseillère politique du Comité international de la CroixRouge. Le présent article ne reflète toutefois pas nécessairement les vues du CICR et n'engage que son auteur.

2.. Cuche D., La Notion de culture dans les sciences sociales, $3^{\mathrm{e}}$ édition, Paris, Editions La Découverte, 2004 ; Wimmer A., Nationalist Exclusion and Ethnic Conflict, Shadows of Modernity, Cambridge, Cambridge University Press, 2002, pp. 19-41.

3.. Monsutti, A., Guerres et migrations, Réseaux sociaux et stratégies économiques des Hazaras d'Afghanistan, Neuchâtel, Editions de l'Institut d'ethnologie, Paris ; Editions de la Maison des Sciences de l'Homme, 2004, pp. 40-54, qui concernent les nouvelles approches du phénomène migratoire, le transnationalisme et la mondialisation.

4.. La Liberté culturelle dans un monde diversifié, Rapport mondial sur le développement humain 2004, Programme des Nations Unies pour le Développement (PNUD), Paris, Economica, 2004, pp. 42-43.

5.. Thual F., Les Conflits identitaires, Paris, Ellipses, Edition Marketing, 1995. 
6.. La Liberté culturelle dans un monde diversifié, op.cit, p. 42.

7.. Spared from the Spear, Traditional Somali Behaviour in Warfare, International Committee of the Red Cross, Somalia Delegation, février 1997.

8.. Dumas A., Le Caucase, Paris, Editions François Bourin, 1990, pp. 48-49 et 94.

9.. Droz Y. (dir.), La Violence et les morts, Eclairage anthropologique sur la mort et les rites funéraires, Chêne-Bourg/Genève, Georg Editeur, collection « Ethnos ", 2003. Ouvrage issu d'une recherche menée pour le CICR, dans le cadre d'un projet sur les disparus en temps de conflit, qui présente la diversité des rites funéraires et le regard de différents anthropologues sur la mort.

10.. Bugnion F., Le Comité international de la Croix-Rouge et la protection des victimes de la guerre, $2^{\mathrm{e}}$ édition, Genève, CICR, 2000.

11.. Le Règlement des conflits tribaux au Yémen, 17 octobre 2002. Document d'archives (interne), DEL 05712.

12. Mourey A., Manuel de nutrition pour l'intervention humanitaire, Genève, CICR, 2004, p. 242 ; voir également p. 190 (impact de la culture sur les mécanismes de sécurité en matière nutritionnelle) et p. 155 (déterminisme culturel, qui intervient lorsque des individus s'organisent en société pour augmenter leurs chances de survie et répondre à leurs besoins).

13.. Jolly J., Position Paper ; Hygiene Promotion, South Sudan, 2003, 3 juin 2004, Document d'archives (interne). LOK 03/200.

14.. Bugnion F., « La genèse de la protection juridique des biens culturels en cas de conflit armé ", Revue internationale de la Croix-Rouge, vol. 86, nº54.

15. Le Statut de la Cour pénale internationale, adopté à Rome le 17 juillet 1998, qualifie de crimes de guerre « [...] le fait de diriger intentionnellement des attaques contre des bâtiments consacrés à la religion, à l'enseignement, à l'art, à la science ou à l'action caritative, des monuments historiques [...] à condition qu'ils ne soient pas des objectifs militaires ", articles 8.2.b (ix) du Statut de Rome. Voir également article 8.2.e (iv). Cette interdiction porte sur les actes commis lors de conflits internationaux et non internationaux. 16.. Dutli M.T., avec la collaboration de Martignoni J.B. et Gaudreau J., Protection des biens culturels en cas de conflit armé, Rapport d'une réunion d'experts (Genève, 5-6 octobre 2000), Genève, CICR, novembre 2001 ; La Protection des biens culturels en cas de conflit armé, Rapport sur le suivi de la résolution 11 du Conseil des Délégués de 2001, document préparé par la Croix-Rouge britannique en consultation avec le Comité international de la Croix-Rouge, Genève, juillet 2003, soumis au Conseil des Délégués, Genève, 30 novembre - 2 décembre 2003, CD 2003 - 8.5/1.

17.. Diallo Y., Traditions africaines et droit humanitaire, Similitudes et divergences, Genève, CICR, 1976.

18. Dary C.F., El derecho internacional humanitario y el ordén juridico maya : una perspectiva historico-cultural, Guatemala, Flasco, 1997.

19.. Chaves G., « L'Approche interculturelle » pour la promotion du droit international au CICR, 1998-1999, (DC/COM/EDUC 00/81, 15.06.00), étude interne menée sous la direction d'Edith Baeriswyl.

20. Projet ponctuel mené par le CICR en Colombie, en 1998, à l'occasion du Mondial de football ; ce projet intitulé « Juege Limpio » (spots de télévision, radio, campagnes d'affichage) faisait une analogie entre les règles du droit humanitaire et les règles à respecter dans le football. Le CICR espérait, par ce biais (notamment la radio) atteindre les jeunes combattants. 
21.. La culture n'est pas un luxe. Coopération et développement : l'aspect culturel, Berne, Direction du développement et de la Coopération, Département Fédéral des Affaires étrangères, septembre 2003.

\section{RÉSUMÉS}

La culture est de plus en plus souvent invoquée comme une cause de conflit, traitée comme un moyen de démarcation, manipulée pour justifier le rejet de l'autre. L'auteur décrit les défis que représente la diversité culturelle pour l'action humanitaire, sur la base de l'expérience du Comité international de la Croix-Rouge. Une expérience unique en son genre, une forme de rencontre de l'universel et du local, d'où émerge une idée forte : la culture n'est pas un tout homogène, hérité du passé, immuable et enfermé dans les frontières de l'Etat. Le discours sur le choc des cultures ne prend pas assez en considération le caractère évolutif de cultures qui se déterritorialisent et renforce une logique de confrontation plutôt que de mettre en exergue la richesse de la diversité. Il est temps que les êtres humains réapprennent à communiquer, à l'heure de la mondialisation et de la révolution technologique de l'information, pour que cessent la déshumanisation de l'ennemi, l'exclusion de la différence et les attaques contre le patrimoine commun de l'humanité.

Cultural differences are cited with increasing frequency as a cause of conflict. They are also viewed as a means of categorizing individuals and are exploited to justify rejection of those individuals. The author illustrates the challenges of cultural diversity for humanitarian action through her experience of the work for the International Committee of the Red Cross. Humanitarian endeavour of this type provides a unique encounter between the universal and the local from which a striking idea emerges: a culture does not constitute one homogeneous bloc handed down whole and unalterable by the forefathers and now preserved intact within the national frontiers. The notion of culture clash takes insufficient account of the fact that cultures which migrate geographically also change. And that notion serves to heighten confrontationalism rather than stressing the cultural wealth that diversity provides. It is time especially in a world marked by globalization and revolutionary advances in communication technology - for human beings to relearn the art of communication and to stop dehumanizing the enemy, ostracizing people who are different, and attacking humanity's shared heritage.

\section{INDEX}

Mots-clés : humanitaire

\section{AUTEUR}

\section{MARION HARROFF-TAVEL}

Marion Harroff-Tavel est conseillère politique du CICR. Ses récentes publications incluent entre autres « la diplomatie humanitaire du CICR », « Does it still make sense to be neutral? », « La 
guerre a-t-elle jamais une fin ? L'action du Comité international de la Croix-Rouge lorsque les armes se taisent ». 